Click www.researchjournal.co.in/online/subdetail.html to purchase.

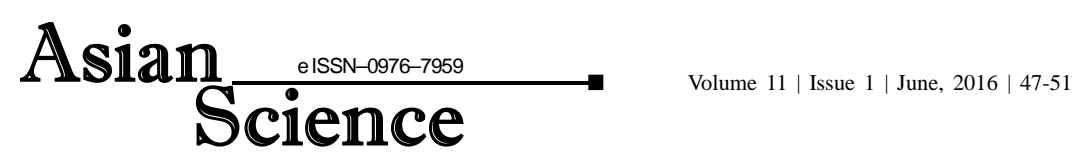

DOI : 10.15740/HAS/AS/11.1/47-51

Visit us | www.researchjournal.co.in

RESEARCH PAPER

\title{
A comparative study of phytochemical screening in plant Hemidesmus indicus (L.) R.Br. collected from different geographical regions of Telangana state
}

\author{
R. SUMAN KUMAR*, P. RAMCHANDRA REDDY, S. GANGADHAR RAO AND K. NETHAJI \\ Department of Botany, University College of Science, Osmania University, HYDERABAD (TELANGANA) INDIA
}

\begin{abstract}
Hemidesmus indicus belongs to the family Apocynaceae, which is used widely as an important medicinal plant. The extracts from the root are used as a coolant and a blood-purifier and is used in many forms. In the present study, emphasis was given on phytochemical screening of root extract and to select an elite species of the above plant with more number of phytochemicals. The plant material was collected from six geographical locations viz., Mahabubnagar, Warangal, Nalgonda, Nizamabad, Karimnagar and Adilabad, which are with different edaphic and climatic conditions of Telangana State, India are designated as site I to VI, respectively. Fourteen phytochemicals were tested for their maximum and minimum presence and the extractions were prepared in aqueous, acetone, ethanol, petroleum ether and chloroform. The results are very clear that the root extracts of plants collected from site IV, V and VI are showing maximum number of phytochemicals and on the other hand plants from site III is showing minimum number of phytochemicals. The present study helps future researchers and the academicians to collect the plant which yield more number of phytochemicals and further it opens a new era of research to quantify and extract the pure compound from the above site plants.
\end{abstract}

Key Words : Hemidesmus indicus, Apocynaceae, Medicinal plant, Phytochemical screening

View point paper : Kumar, R. Suman, Reddy, P. Ramchandra, Rao, S. Gangadhar and Nethaji, K. (2016). A comparative study of phytochemical screening in plant Hemidesmus indicus (L.) R.Br. collected from different geographical regions of Telangana state. Asian Sci., 11 (1): 47-51, DOI : 10.15740/HAS/AS/11.1/47-51.

\footnotetext{
* Author for correspondence

R. Suman Kumar, Department of Botany, University College of Science, Osmania University, HYDERABAD (TELANGANA) INDIA (Email: sumanvandy2008@gmail.com)
} 